\title{
How the oxygen tolerance of a [NiFe]-hydrogenase depends on quaternary structure
}

\author{
Philip Wulff $^{1} \cdot$ Claudia Thomas $^{1} \cdot$ Frank Sargent $^{2} \cdot$ Fraser A. Armstrong $^{1}$
}

Received: 31 October 2015 / Accepted: 23 December 2015 / Published online: 9 February 2016

(C) The Author(s) 2016. This article is published with open access at Springerlink.com

\begin{abstract}
Oxygen-tolerant' [NiFe]-hydrogenases can catalyze $\mathrm{H}_{2}$ oxidation under aerobic conditions, avoiding oxygenation and destruction of the active site. In one mechanism accounting for this special property, membrane-bound [NiFe]-hydrogenases accommodate a pool of electrons that allows an $\mathrm{O}_{2}$ molecule attacking the active site to be converted rapidly to harmless water. An important advantage may stem from having a dimeric or higher-order quaternary structure in which the electron-transfer relay chain of one partner is electronically coupled to that in the other. Hydrogenase-1 from E. coli has a dimeric structure in which the distal $[4 \mathrm{Fe}-4 \mathrm{~S}]$ clusters in each monomer are located approximately $12 \AA$ apart, a distance conducive to fast electron tunneling. Such an arrangement can ensure that electrons from $\mathrm{H}_{2}$ oxidation released at the active site of one partner are immediately transferred to its counterpart when an $\mathrm{O}_{2}$ molecule attacks. This paper addresses the role of long-range, inter-domain electron transfer in the mechanism of $\mathrm{O}_{2}$-tolerance by comparing the properties of monomeric and dimeric forms of Hydrogenase- 1 . The results reveal a further interesting advantage that quaternary structure affords to proteins.
\end{abstract}

Keywords Electron transfer · Iron-sulfur clusters · Quaternary structure $\cdot$ Hydrogen $\cdot$ Hydrogenase

Fraser A. Armstrong

fraser.armstrong@chem.ox.ac.uk

1 Department of Chemistry, University of Oxford, Oxford, UK

2 Division of Molecular Microbiology, School of Life Sciences, University of Dundee, Dundee DD1 5EH, UK

\section{Introduction}

Hydrogenases, microbial metalloenzymes that produce or oxidize $\mathrm{H}_{2}$, are important for understanding the energy balance and metabolism of microoganisms, in addition to being inspirational models for future hydrogen catalysts $[1,2]$. The active sites of the two main classes, known as $[\mathrm{NiFe}]$ and $[\mathrm{FeFe}]$-hydrogenases, contain the metals $\mathrm{Ni}$ and $\mathrm{Fe}$ (as in [NiFe]-hydrogenases) or just $\mathrm{Fe}$ (as in [FeFe]hydrogenases) in unusual coordination shells that have a $[\mathrm{Fe}(\mathrm{CO})(\mathrm{CN})(\mathrm{RS})]$ subcomplex as a minimal motif. Figure 1 provides structural information that will be relevant for this paper. So-called 'standard' [NiFe]-hydrogenases consist of a large $(\alpha)$ subunit containing the [NiFe]active site and a small $(\beta)$ subunit containing a relay of FeS clusters to transfer electrons. These air-sensitive enzymes have been extensively investigated by crystallography and spectrosocopic techniques with significant input from molecular biology strategies [2]. Attached to an electrode, hydrogenases are extremely efficient electrocatalysts, and protein film electrochemistry (PFE), in which catalytic rate is measured directly as current, has made important contributions to our understanding of their functional properties [3-5].

A special sub-category of [NiFe]-hydrogenases, known as $\mathrm{O}_{2}$-tolerant hydrogenases, have the special property of displaying sustained activity in the presence of $\mathrm{O}_{2}$ [6-10]. These hydrogenases operate because they destroy $\mathrm{O}_{2}$ by rapidly converting it to water, thus avoiding reactive oxygen species that would otherwise oxygenate the active site and render it inactive for long periods-a state/states known as 'Unready' or 'Ni-A' [10-12]. Under $\mathrm{H}_{2}$, membrane-bound $\mathrm{O}_{2}$-tolerant hydrogenases react with $\mathrm{O}_{2}$ to form a $\mathrm{Ni}(\mathrm{III})-\mathrm{OH}$ complex, known as Ni-B ('Ready'), 
Fig. 1 Views of [NiFe]-hydrogenases of relevance to this paper. a The $(\alpha \beta)$ monomeric [NiFe]-hydrogenase from $D$. fructosovorans hydrogenase. b The $(\alpha \beta)_{2}$ dimeric $[\mathrm{NiFe}]-$ hydrogenase from $E$. coli (Hyd-1). This structure (PDB: 4GD3) of the P242C variant with a P-to-C exchange at the medial FeS cluster also shows a cytochrome subunit that is absent from other crystal in Hyd-1: [NiFe] active site and iron sulfur clusters labeled with edge-to-edge electron transfer distances. The position of the $b$-type heme in the membrane anchor is also shown (from the structure of P242C) structures. c The redox centers

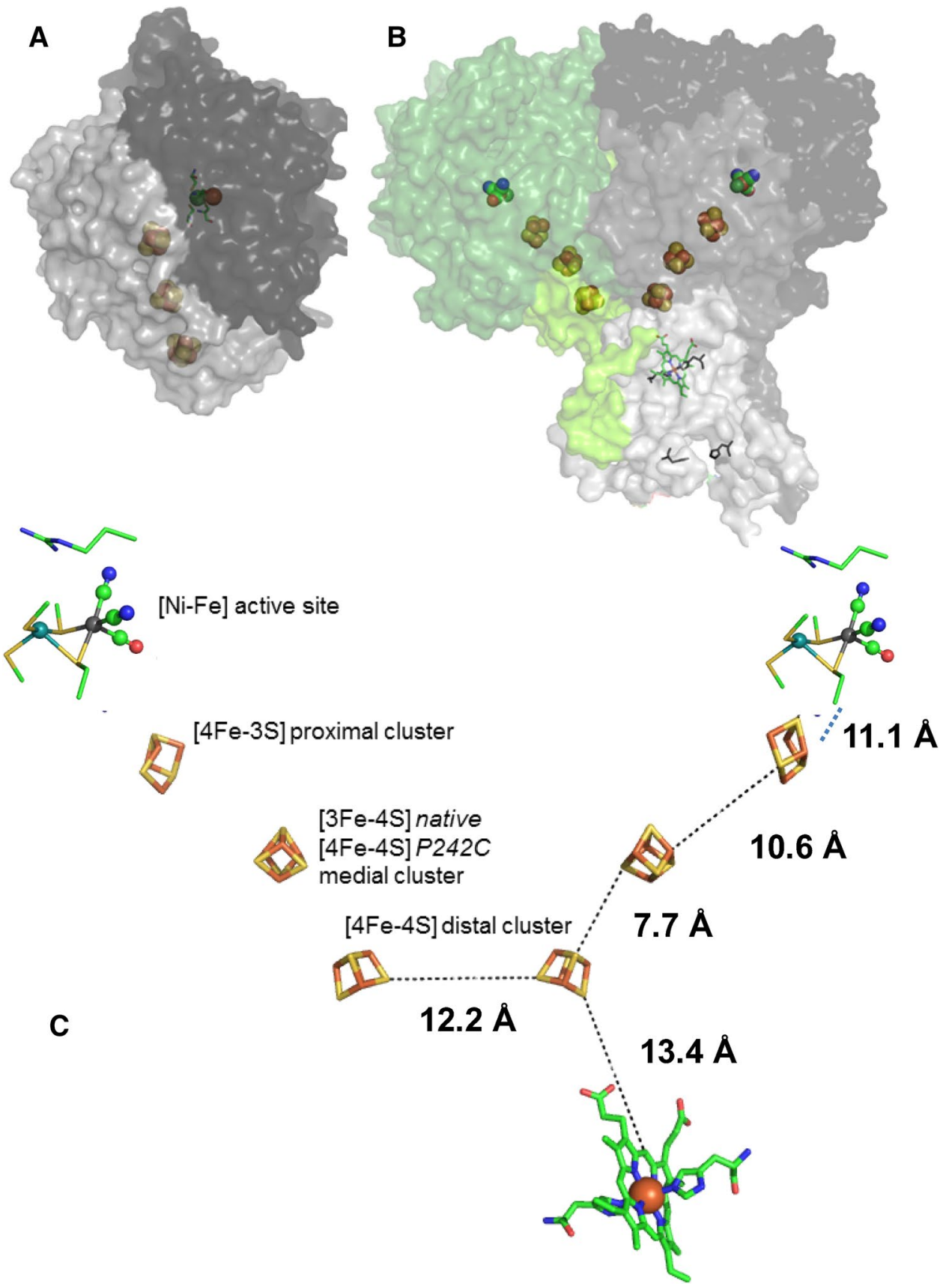

that is rapidly re-activated by reduction to an active $\mathrm{Ni}(\mathrm{II})$ species with release of the $\mathrm{OH}$ ligand. An efficient electron supply thus serves two roles-(a) securing complete reduction of $\mathrm{O}_{2}$, by-passing reactive intermediates, and (b) ensuring rapid re-activation of $\mathrm{Ni}-\mathrm{B}$ (regarded as a resting state). The structures of 'standard' (strongly $\mathrm{O}_{2}$-inhibited) [NiFe] hydrogenases, such as $D$. fructosovorans hydrogenase (Fig. 1a) [1, 13], have been known since 1995, but only recently have the structures of $\mathrm{O}_{2}$-tolerant hydrogenases of the subgroup of membrane-bound respiratory [NiFe]-hydrogenases (MBH) isolated from Ralstonia eutropha H16, Hydrogenovibrio marinus, Escherichia coli and Salmonella enterica, been established [14-17]. These new structures have not only revealed a novel [4Fe-3S] cluster, able to transfer two electrons sequentially $[9,15-$ 18], but they also show interesting quaternary organization that may also be important in conferring $\mathrm{O}_{2}$-tolerance, as discussed below. The MBHs not only contain additional membrane-domain subunits that dissociate upon isolation with detergents, but also exist as oligomers of the minimal $\alpha \beta$ 'heterodimer'.

The crystal structure of Hydrogenase-1 (Hyd-1) from E. coli shows it to be a $(\alpha \beta)_{2}$ dimer, in contrast to the $(\alpha \beta)$ monomer of standard hydrogenases (Fig. 1a, b) [16]. The 
structure supports earlier determination of the molecular mass of Hyd-1 as $200 \pm 20 \mathrm{kDa}$, [19]. It was also known that in vivo, Hyd-1 associates with membrane-intrinsic subunits that contain cytochrome $b[19,20]$. Although the first crystal structure obtained for Hyd-1 did not include its cognate cytochrome $b$ subunit, a subsequent structure obtained for P242C variant (depicted in Fig. 1b) included the membrane-intrinsic subunits in which one cytochrome $b$ remained attached [21]. In the isolation of solubilized Hyd-1, the cytochrome $b$ subunits are normally lost during the homogenization stage.

The distance between the two distal clusters in each half of Hyd-1 is only $12.2 \AA$. It has been proposed that an intersite distance below $14 \AA$ is generally short enough to allow electron tunneling to occur at a sufficient rate that catalysis is not limited [22]. Comparing the distances between the other iron-sulfur clusters in Hyd-1 (ca. 12.2 vs. $7.7 \AA$, 10.6 and $11.1 \AA$ Fig. 1c) therefore suggests that electron exchange between the two distal clusters and thus between the two $(\alpha \beta)$ halves should be feasible. Shomura and coworkers, having solved the similarly heterotetrameric structure of the membrane-bound hydrogenase (MBH) from $H$. marinus, ruled out the possibility that dimerization might be an artifact of crystallization, on the basis that the contact between heteromers adds up to $11 \%$ of the total surface area of the protein and the subunits have precisely matching orientations - the latter observation pointing towards purposeful joint alignment on the cell membrane [15].

In an unusual experiment that shed further light on the importance of long-range intermolecular/interfacial electron transfer in $\mathrm{O}_{2}$ tolerance, Wait and co-workers measured the power characteristics of a membrane-less fuel cell with two carbon electrodes, one modified with Hyd-1 (the $\mathrm{H}_{2}$-oxidizing anode) and the other with bilirubin oxidase (the $\mathrm{O}_{2}$-reducing cathode) [23]. Such an investigation is an electrochemical experiment without a source of potential control or external electrons. The $\mathrm{O}_{2}$-tolerant hydrogenase allows the fuel cell to operate with a non-explosive $\mathrm{H}_{2}$-air mixture; however, use of a weak $\mathrm{H}_{2}$ mixture ( $3 \%$ ) resulted in loss of power, apparently irreversibly, when the load resistance was set sufficiently small to collapse the voltage. The 'short circuit' caused the oxidizing power due to $\mathrm{O}_{2}$ reacting at the cathode to be transmitted directly to the anode: as a result, and without enough $\mathrm{H}_{2}$ to act as counterbalance, Hyd-1 was converted rapidly to Ni-B. Power could not be restored by increasing the resistance, but momentarily connecting a second anode with active Hyd-1 resulted in immediate recovery. This effect was likened to jump-starting a car that has a flat battery, with active hydrogenases on the repairing electrode providing electrons to reactivate the hydrogenases on the fuel cell anode that have been completely converted to the Ni-B state. Volbeda and co-workers suggested that the proximity of the distal clusters in the two halves of Hyd-1 might enable a similar 'jump-start' reactivation of $\mathrm{Ni}-\mathrm{B}$ to operate internally in the $(\alpha \beta)_{2}$ dimer [21].

Oligomer formation can be predicted using PISA (proteins, interfaces, structures and assemblies) software which calculates energies and entropies of dissociation into monomers [24]. Table 1 shows an assessment of current [NiFe] hydrogenase structures, evaluated with Pymol and PISA. All the $\mathrm{O}_{2}$-tolerant hydrogenases are membrane-bound in vivo and all but the $R$. eutropha MBH show dimers of heterodimers $(\alpha \beta)_{2}$ in the crystal structure, although it was reported that $R$. eutropha $\mathrm{MBH}$ may form a trimeric $(\alpha \beta \gamma)_{3}$ supercomplex including cytochrome $b$, based on a static light scattering analysis [25]. For $\mathrm{O}_{2}$-tolerant hydrogenases the free energy of dissociation $\left(\Delta G^{\text {diss }}\right)$ within the $(\alpha \beta)$ heterodimer is twice as large as the corresponding interheterodimer $(\alpha \beta)$ values ( 60 vs. $30 \mathrm{kcal} / \mathrm{mol}$ ), and higher than for standard hydrogenases. The hydrogenase from $A$. vinosum is the only standard hydrogenase found to crystallize as a dimer, albeit with only half the calculated $\Delta G^{\text {diss }}$. The distance between the two distal FeS clusters, averaging around $12.5 \AA$ in the $\mathrm{O}_{2}$-tolerant enzymes, is higher in the A. vinosum hydrogenase, at $14 \AA$.

An interesting observation was reported recently, in which the full $(\alpha \beta \gamma)_{3}$ complex of $R$. eutropha $\mathrm{MBH}$ was studied by PFE, utilizing a tethered lipid bilayer to immobilize the enzyme on a gold electrode [26]. Unlike the normal soluble form that has been extensively studied by PFE at a graphite electrode, the $(\alpha \beta \gamma)_{3}$ complex did not inactivate anaerobically when poised at a high potential, and re-activation after exposure to $\mathrm{O}_{2}$ occurred spontaneously even at high potentials when $\mathrm{O}_{2}$ was removed.

The question is therefore raised-what role could extended inter-heterodimer electron transfer play in protecting a hydrogenase against $\mathrm{O}_{2}$ ? Such a protection role would represent a further example of the importance of quaternary structure in biology [27]. We have now investigated the significance of the $(\alpha \beta)_{2}$ structure of solubilized Hyd-1 in relation to hydrogenase $\mathrm{O}_{2}$-tolerance. This required a systematic step-by-step strategy-establishing how to obtain the monomeric $(\alpha \beta)$ form and separate it from the $(\alpha \beta)_{2}$ dimer, investigating the stability and catalytic properties of the $(\alpha \beta)$ form, comparing the $\mathrm{O}_{2}$-tolerances of $(\alpha \beta)$ and $(\alpha \beta)_{2}$, and finally devising a model that accounts for the differences.

\section{Materials and methods}

The general procedures for obtaining purified Hyd-1 from $E$. coli cells were based on those previously established [6]. Samples were stored in liquid $\mathrm{N}_{2}$ as required. Size exclusion chromatography (SEC) columns were calibrated with 
Table 1 Oligomeric assembly of all known [NiFe] hydrogenase structures: based on crystal structure visual assessment and PISA (proteins, interfaces, structures and assemblies) software calculations [24], the oligomeric assembly of large subunit $\alpha$ and small subunit $\beta$ is presented along with PISA estimates of the free energy of assembly dissociation $\left(\Delta G^{\text {diss }}\right)$ in $\mathrm{kcal} /$ mol of large and small subunit within one heteromer $(\alpha: \beta)$ and between two heteromers $(\alpha \beta):(\alpha \beta)$, where applicable

\begin{tabular}{|c|c|c|c|c|}
\hline \multirow[t]{2}{*}{ Organism (hydrogenase) } & \multirow[t]{2}{*}{ Assembly } & \multicolumn{2}{|c|}{$\Delta G^{\mathrm{diss}}[\mathrm{kcal} / \mathrm{mol}]$} & \multirow[t]{2}{*}{ Distal cluster proximity/Å } \\
\hline & & $\alpha: \beta$ & $(\alpha \beta):(\alpha \beta)$ & \\
\hline E. coli $\mathrm{Hyd}-1^{\mathrm{a}}$ & $(\alpha \beta)_{2}$ & 60 & 32 & 12.2 Å Endnote library Wulff.enl \\
\hline H. marinus $\mathrm{MBH}^{\mathrm{a}}$ & $(\alpha \beta)_{2}$ & 64 & 27 & 12.6 \\
\hline S. enterica $\mathrm{Hyd}-5^{\mathrm{a}}$ & $(\alpha \beta)_{2}$ & 62 & 32 & 12.7 \\
\hline R. eutropha $\mathrm{MBH}^{\mathrm{a}}$ & $(\alpha \beta)^{b}$ & 57 & - & - \\
\hline A. vinosum $\mathrm{Hyd}$ & $(\alpha \beta)_{2}$ & 53 & 16 & 14.0 \\
\hline D. fructosovorans Hyd & $(\alpha \beta)$ & 53 & - & - \\
\hline D. gigas Hyd & $(\alpha \beta)$ & 54 & - & - \\
\hline D. desulfuricans Hyd & $(\alpha \beta)$ & 51 & - & - \\
\hline D. vulgaris Hyd & $(\alpha \beta)$ & 57 & - & - \\
\hline D. baculatum $\mathrm{Hyd}^{\mathrm{c}}$ & $(\alpha \beta)$ & 53 & - & - \\
\hline D. vulgaris $\mathrm{H} \mathrm{Hyd}^{\mathrm{c}}$ & $(\alpha \beta)$ & 30 & - & - \\
\hline
\end{tabular}

The proximity of adjoining distal iron sulfur clusters was measured with the Pymol software. Organisms and enzyme PDB codes: Escherichia coli (3UQY), Hydrogenovibrio marinus (3AYY), Salmonella enterica (4C3O), Ralstonia eutropha (3RGW), Allochromatium vinosum (3MYR), Desulfovibrio fructosovorans (1FRF), Desulfovibrio gigas (1FRV), Desulfovibrio desulfuricans (1E3D), Desulfovibrio vulgaris (1WUL), Desulfovibrio vulgaris Hildenborough (2WPN), Desulfomicrobium baculatum (4KN9)

a Oxygen tolerant enzyme

b Described as trimeric $(\alpha \beta \gamma)_{3}$, including cytochromes, by Frielingsdorf et al. in gel filtration experiments but not in the crystal structure [25]

${ }^{c}[\mathrm{NiFeSe}]$ hydrogenase the Sigma Aldrich MWGF1000 kit of protein standards. Since the elution volume corresponding to a certain molecular mass depended significantly on the detergent used, and varied with each repacking, the column was recalibrated each time for each detergent. Alcohol dehydrogenase $(\mathrm{ADH})$ protein standard $(150 \mathrm{kDa})$ was used between sample runs to help evaluate sample peak positions and confirm column integrity.

Protein samples for native electrophoresis were prepared by addition of sample buffer (Invitrogen, final concentration $50 \mathrm{mM}$ BisTris, $6 \mathrm{~N} \mathrm{HCl}, 50 \mathrm{mM} \mathrm{NaCl}, 10 \%$ w/v glycerol, $0.001 \%$ Ponceau S, pH 7.2). NativeMarkTM Unstained Protein Standard (Invitrogen) was used as a reference. The Anode Buffer consisted simply of Running Buffer (50 mM BisTris, $50 \mathrm{mM}$ Tricine, $\mathrm{pH}$ 6.8) while the Cathode Buffer included 20× Cathode Additive $(0.4 \%$ Coomassie $\mathrm{r}$ G-250). The gel (pre-cast 4-16\% BisTris, Invitrogen) was run at $150 \mathrm{~V}$ for ca. $130 \mathrm{~min}$, using the XCell SureLockTM electrophoresis system (Life Technologies). The gel was developed as follows: incubation in ca. $100 \mathrm{~mL}$ fixing solution (40\% methanol, $10 \%$ acetic acid) for approx. $60 \mathrm{~s}$ in the microwave at ca. $700 \mathrm{~W}$, followed by $15-20 \mathrm{~min}$ at room temperature on a gel shaker. Subsequently the gel was transferred to destaining solution (8\% acetic acid) and incubated, first in the microwave for $60 \mathrm{~s}$ at $700 \mathrm{~W}$ and then at room temperature on the shaker until satisfactory.
Protein samples for denaturing electrophoresis were prepared by addition of $4 \times$ LDS sample buffer (Invitrogen) (total volume $10 \mu \mathrm{L}$ ) and heating for $10 \mathrm{~min}$ at $70{ }^{\circ} \mathrm{C}$. PageRuler $^{\circledR}$ pre-stained protein ladder (Thermo Scientific) was used as a reference standard. The samples were loaded onto a NuPAGEr 4-12 \% Bis-Tris pre-cast gel (Invitrogen) and run at $200 \mathrm{~V}$ for ca. 50 min in MOPS running buffer (50 mM MOPS, $50 \mathrm{mM}$ Tris base, $1 \mathrm{mM}$ EDTA, $0.1 \%$ SDS, pH 7.7) using the XCell SureLockTM electrophoresis system (Life Technologies). Gels were developed by incubation in Coomassie staining solution $(0.25 \%$ Coomassie brilliant blue, $50 \%$ ethanol, $10 \%$ glacial acetic acid, deionized water) for ca. $10 \mathrm{~min}$ at a temperature between 50 and $60{ }^{\circ} \mathrm{C}$ followed by subsequent destaining until satisfactory (20\% ethanol, $10 \%$ glacial acetic acid, deionised water).

Procedures for isotope ratio mass spectrometry and hydrogen peroxide assays were carried out as described recently [11]. Protein film electrochemistry methods, including voltammetry and chronoamperometry were based on experiments described in the recent paper by Evans et al. [7]. All reagents used to prepare samples for solution assays or protein film electrochemistry were of analytical grade and high-purity water (Milli-Q, Millipore $18 \mathrm{M} \Omega \mathrm{cm}$ ) was used throughout. All gases were supplied by BOC. 


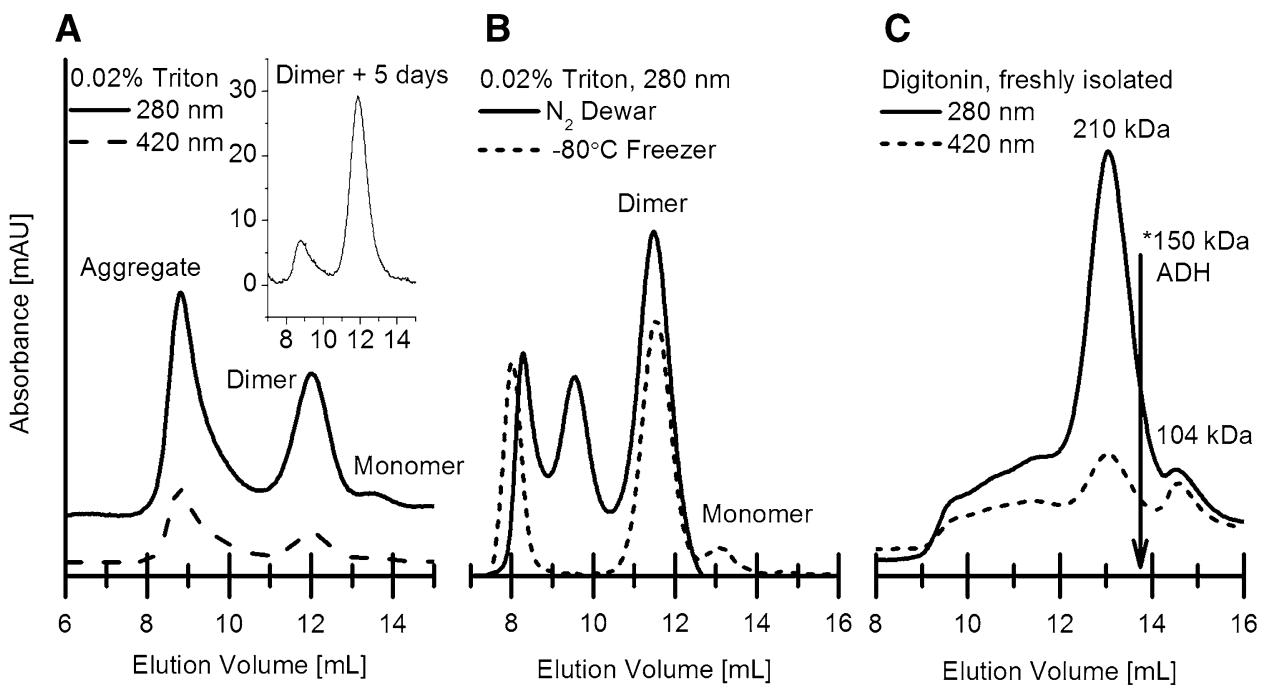

Fig. 2 Hyd-1 size exclusion chromatography with Triton X-100 and digitonin: all samples shown were first purified by Ni-NTA affinity chromatography. The absorbance, at 420 and/or $280 \mathrm{~nm}$, is shown across the elution volume. a Separation of Hyd-1 with Triton X-100, exchanged from Ni-NTA purification buffer $(20 \mathrm{mM}$ Tris, $350 \mathrm{mM}$ $\mathrm{NaCl}, 0.02 \%$ Triton; see "Materials and methods") into running buffer prior to the experiment. The peak at $12 \mathrm{~mL}$ was isolated and stored at $4{ }^{\circ} \mathrm{C}$ for 5 days before being subjected to chromatography again, as shown in the inset. b Separation of defrosted Hyd-1 sam-

\section{Results}

\section{Separation of oligomeric states of Hyd-1}

Figure 2a shows a Hyd-1 oligomer separation carried out in buffer containing $0.02 \%$ Triton X-100. Soluble aggregate is found near the void (around $8-9.5 \mathrm{~mL}$ ). A large, well-defined peak at $12 \mathrm{~mL}$ and a much smaller peak at $13.5 \mathrm{~mL}$, corresponding to molecular masses of approximately 220 and $110 \mathrm{kDa}$, respectively, are assigned to dimer and monomer forms of Hyd-1. Significant absorbance at $420 \mathrm{~nm}$ due to iron-sulfur clusters and heme is found for both aggregate and the dimer peaks. The inset (Fig. 2a) shows an SEC analysis of the dimer fraction after 5 days storage at $4{ }^{\circ} \mathrm{C}$. The fact that most protein elutes at the same volume $(12 \mathrm{~mL})$ suggests that the dimeric form is the stable state. However, the reproducibility of the separation experiment with Triton X-100 (major panel Fig. 2a) was poor, especially with regard to the monomer, the low yield of which is clear from analysis of the isolation products by Native gel electrophoresis, as shown in Fig. 3a. The elution profile depended further on how isolated Hyd-1 is stored. Replacing Triton X-100 with digitonin, a detergent used to purify $R$. eutropha membrane-bound hydrogenase (MBH) in a fragile multimeric complex with its native cytochrome $b_{562}$, led to ples from the liquid nitrogen dewar and a $-80{ }^{\circ} \mathrm{C}$ freezer, with Triton $\mathrm{X}-100$. The samples were thawed immediately before applying to the column. c Freshly isolated Hyd-1 was incubated for $2 \mathrm{~h}$ with ca. $1 \%$ digitonin before chromatographic separation in running buffer containing $0.007 \%$ digitonin. The arrow and asterisk mark the peak position of $150 \mathrm{kDa}$ alcohol dehydrogenase $(\mathrm{ADH})$ protein standard. Other conditions: flow rate $0.15 \mathrm{~mL} / \mathrm{min}$, superdex $200 \mathrm{HR}$ column (10/30), $\mathrm{pH} 7.0,50 \mathrm{mM}$ sodium phosphate, $0.10 \mathrm{M} \mathrm{NaCl}, 4{ }^{\circ} \mathrm{C}$. The column was repacked between experiments $\mathbf{a}, \mathbf{b}$ and $\mathbf{c}$

more reliable isolation of Hyd-1 monomer [25]. The best results were obtained by pre-incubating freshly purified samples in buffer containing ca. $1 \%(\mathrm{wt} / \mathrm{vol})$ digitonin then using just $0.007 \%$ digitonin in the running buffer to minimize detergent precipitation. The molecular masses of the protein peaks identified as 'Dimer' and 'Monomer', calculated relative to a full calibration, are $210 \mathrm{kDa}$ and $104 \mathrm{kDa}$, respectively. Particularly notable is the presence of two distinct $\mathrm{A}_{420}$ peaks pairing with the $\mathrm{A}_{280}$ dimer and monomer peaks.

To evaluate the subunit composition of the aggregate and putative dimer and monomer peaks isolated from Triton X-100 and digitonin SEC experiments (Fig. 2b/c), denaturing electrophoresis was carried out (Fig. 3b). All samples show characteristic large $(64.6 \mathrm{kDa})$ and small $(36.8 \mathrm{kDa})$ subunit bands just below the 70 and $40 \mathrm{kDa}$ marker bands, demonstrating that the monomer and dimer fractions (at approximately 110 and $220 \mathrm{kDa}$ total mass) are structurally intact and consist of at least one and two assemblies, respectively, of a large and small subunit each. Some lanes are slightly overloaded (widening of the large subunit band) which is somewhat unavoidable in the search for fainter bands. While the overloading prevents a truly reliable quantitative comparison of band density, the Triton $\mathrm{X}-100$ aggregate appears to have a particularly low proportion of small subunit. 
Fig. 3 Native and SDS polyacrylamide gel electrophoresis of Hyd-1 samples: a native PAGE of isolated full Hyd-1 WT, b SDS PAGE of separated Hyd-1 (WT) fractions. Nonrelevant lanes have been omitted

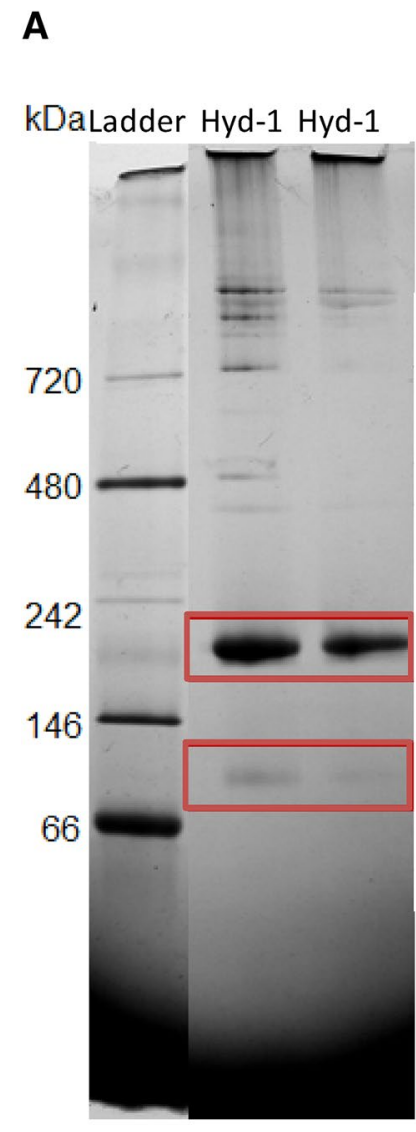

B

Digitonin

Hyd-1

Triton X-100

Hyd-1

kDa Ladder Dimer Monomer Aggr. Dimer Monomer

170

130

100

70

55

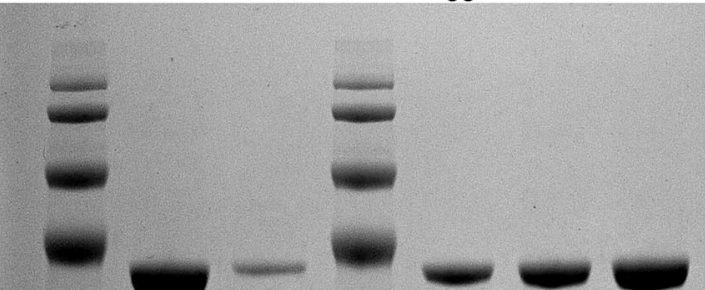

40

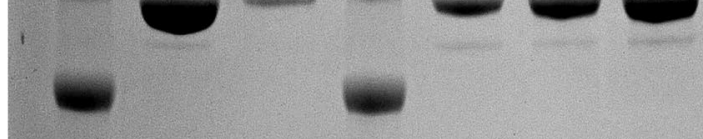

35

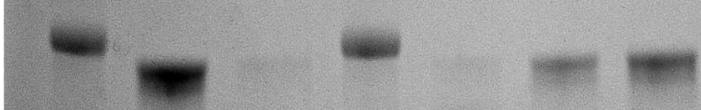

25

15

10

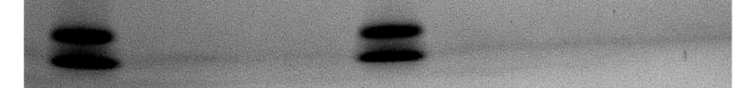

\section{Reactivation and $\mathrm{O}_{2}$ reduction in solution}

Hydrogen oxidation by hydrogenases in solution is easily measured by monitoring the increase in absorbance at $604 \mathrm{~nm}\left(A_{604}\right)$ due to enzymatic reduction of benzyl viologen in the presence of $\mathrm{H}_{2}$ [6]. When using enzyme samples that have previously been activated under $\mathrm{H}_{2}$ then exposed to air to cause inactivation, a lag phase in which there is no change in $A_{604}$ is commonly observed at the beginning of the assay, when all the viologen is in the oxidized state. The lag phase arises because enzyme reactivation depends on the supply of electrons (transferred to viologen) originating from $\mathrm{H}_{2}$ oxidation by those sites that are active: there are no electrons available at the start of the experiment, and few active enzyme molecules to generate them.

The lag phases of dimer and monomer samples were compared. Initial hydrogen oxidation assays indicated that dimer samples were more than twice as active as monomer, based on protein concentrations determined by Bradford assay. However, the Bradford assay is very susceptible to, and easily biased by, the presence of detergents, that are essential for sample preparation, storage and use. Reagent binding might also be significantly affected by the level of protein aggregation. Determination of protein concentration by UV-vis spectroscopy $\left(A_{280}\right)$ yielded turnover rates that were closer in value. To compare different measurements in the light of this uncertainty, the amount of enzyme used in the eventual solution-based reactivation assays was adjusted to yield samples of equal final activity and not apparent protein concentration.

Figure 4a shows a typical result of the lag phase experiment, in which previously activated dimer and monomer samples were exposed to air for several hours before the assay. Immediately after injection into $\mathrm{H}_{2}$-saturated benzyl viologen buffer, the absorbance at $604 \mathrm{~nm}$ was recorded over time. The eventual rate of viologen reduction in the samples was adjusted to be as similar as possible; in this case approx. $5.9 \mu \mathrm{M} \mathrm{s}^{-1}$ for the dimer and $6.7 \mu \mathrm{M} \mathrm{s}^{-1}$ for the monomer solution. The lag phases differ greatly between monomer and dimer. Figure $4 \mathrm{~b}$ compares the lag phases observed in three sets of experiments, carried out using enzyme from three separate preparations. Although both overall activity and length of lag phase vary between different Hyd-1 preparations, the difference between dimer and monomer for each individual preparation was clear and consistent: the lag phase of the monomer is always slightly more than twice as long as that of the dimer.

Oxygen-18 reduction experiments for dimer and monomer samples were carried out using isotope ratio mass spectrometry to detect the amount of $\mathrm{H}_{2}^{18} \mathrm{O}$ formed. The 
Fig. 4 Benzyl Viologen reduction lag phase assay: a reduction of benzyl viologen $\left(\varepsilon_{604}=9.82 \mathrm{mM}^{-1} \mathrm{~cm}^{-1}\right.$ for reduced form) monitored over time for Hyd-1 dimer and monomer solutions. Conditions: $\mathrm{H}_{2}$-saturated buffer, $\mathrm{pH}$ 7.0, $50 \mathrm{mM}$ sodium phosphate, $0.10 \mathrm{M} \mathrm{NaCl}, 0.01 \%$ digitonin, room temperature. b Comparisons of the length of the lag phase for three separate experiments with enzymes from three separate preparations. The time point of the end of the lag phase was determined by eye
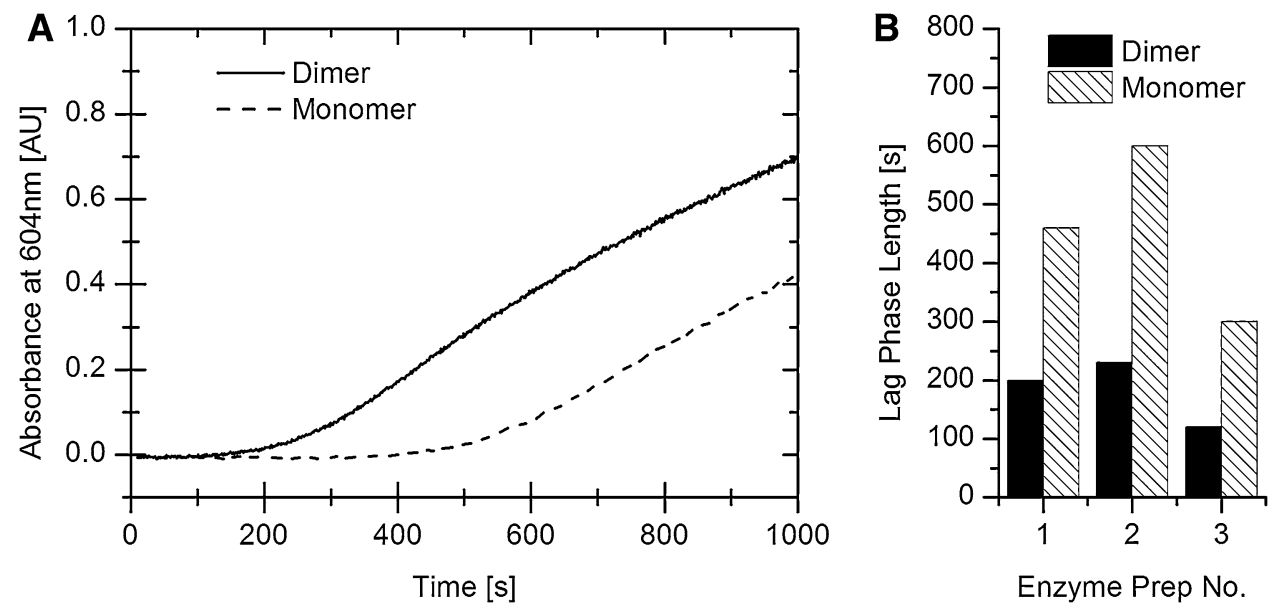

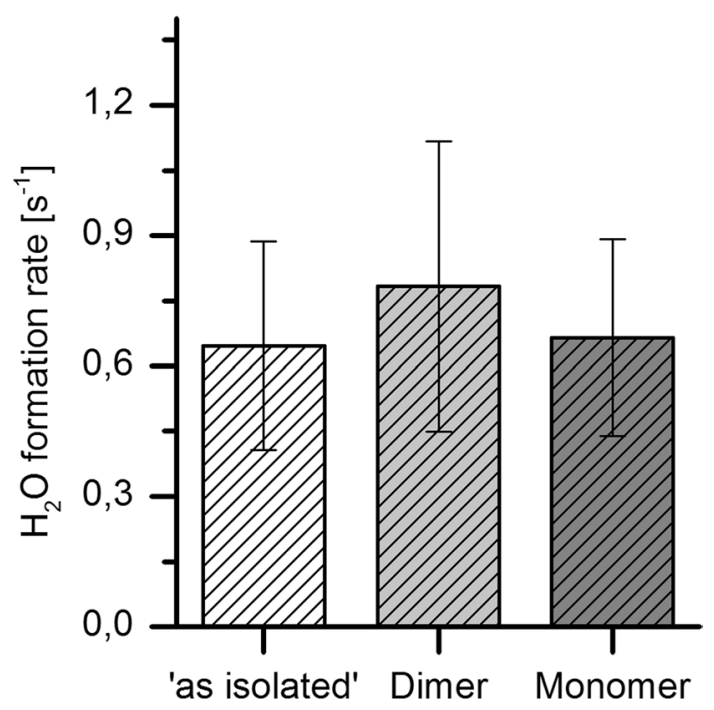

Fig. 5 Rate of formation of $\mathrm{H}_{2}^{18} \mathrm{O}$ by dimer and monomer forms of Hyd-1: the rate of water formation $\left(\mu \mathrm{M} \mathrm{H}_{2}^{18} \mathrm{O}\right.$ per $\mu \mathrm{M}$ Hyd-1) compared to blank controls is given for 'as isolated' Hyd-1 and resolved dimer and monomer forms. The error bars show the standard deviation across 18, 3 and 3 measurements, respectively. The concentration of $\mathrm{H}_{2}^{18} \mathrm{O}$ was measured by isotope ratio mass spectrometry as described previously [11]. The experiments were conducted under an atmosphere of $90 \% \mathrm{H}_{2}$ and $10 \%{ }^{18} \mathrm{O}_{2}$ at $\mathrm{pH} 7.0$ and $20{ }^{\circ} \mathrm{C}$

methodology was as described recently [11]. Due to the limited amount of monomer available, the following protocol was used. First, the concentration of dimer samples was determined by Bradford assay, then the absorbance at $280 \mathrm{~nm}\left(\mathrm{~A}_{280}\right)$ was recorded by UV-vis spectroscopy to obtain a molar absorption coefficient from which the concentration of monomer samples could also be determined. The concentration of enzyme is expressed with reference to the functional monomer containing one active site and having a mass of $101 \mathrm{kDa}$. Figure 5 shows the results obtained from eighteen data points in Ref. [11] where an $\mathrm{H}_{2}^{18} \mathrm{O}$ formation rate of $0.65 \mathrm{~s}^{-1}$ was obtained; this compares with rates obtained (three datum points) from samples incubated for 4,10 and $14 \mathrm{~h}$ for dimer $\left(0.78 \mathrm{~s}^{-1}\right)$ and monomer $\left(0.67 \mathrm{~s}^{-1}\right)$. Long incubation times were needed to accumulate enough products for mass spectrometry measurements, due to Hyd-1 monomer concentrations being as low as $0.06 \mu \mathrm{M}$.

\section{Protein film electrochemistry of dimer and monomer}

To evaluate any obvious electrochemical differences between dimer and monomer forms of Hyd-1, cyclic voltammetry was performed on enzyme films grown using the two different fractions on a pyrolytic graphite edge (PGE) electrode using published procedures [3].

Figure 6a shows cyclic voltammetry experiments carried out with monomer and dimer forms. The potential was scanned at $1 \mathrm{mV} \mathrm{s}^{-1}$ and the PGE electrode was rotated at $3000 \mathrm{rpm}$, conditions found to give steady-state voltammetry free of time dependence or mass-transport limitations. The line shows the average current for forward and reverse scans. The dimer yielded significantly higher catalytic current than the monomer (an approximate fourfold difference being typical) irrespective of whether the film was obtained through application of more or equally concentrated dimer solution relative to the monomer. Only in experiments with very dilute monomer samples (a symptom of very low monomer yields in early isolation experiments) were larger differences in total current observed. The plot in Fig. 6a initially suggests that the monomer has a more positive onset potential (the potential at which the catalytic current begins to rise) so a normalization procedure was devised to allow a better comparison of the two results. Figure $6 \mathrm{~b}$ compares the first derivative (slope) of the monomer and dimer voltammograms, which locates a characteristic potential at which the rate increases most steeply. The potentials of maximum rate of current change are very similar for monomer and dimer, at approximately -203 
Fig. 6 Protein film voltammetry of dimer and monomer forms of Hyd-1: a averaged forward and backward scans (scan rate $1 \mathrm{mV} \mathrm{s}^{-1}$ ) of dimer and monomer films on a rotating PGE electrode. b First derivative of the averaged cyclic voltammograms from panel $\mathbf{a}$. c Voltammograms normalized with respect to the current at the potential of the maximum derivative. d Linear sweep scans of dimer and monomer films, slowly swept from +0.42 to $-0.44 \mathrm{~V}$ vs. SHE at $0.1 \mathrm{mV} \mathrm{s}^{-1}$, to monitor reactivation of the anaerobically inactivated oxidized state $(\mathrm{Ni}-\mathrm{B})$. As in panel $\mathbf{c}$, the voltammograms are normalized to the current at the potential of maximum derivative. Common conditions: $100 \% \mathrm{H}_{2}$, pH 6.5, electrode rotation rate $3000 \mathrm{rpm}$
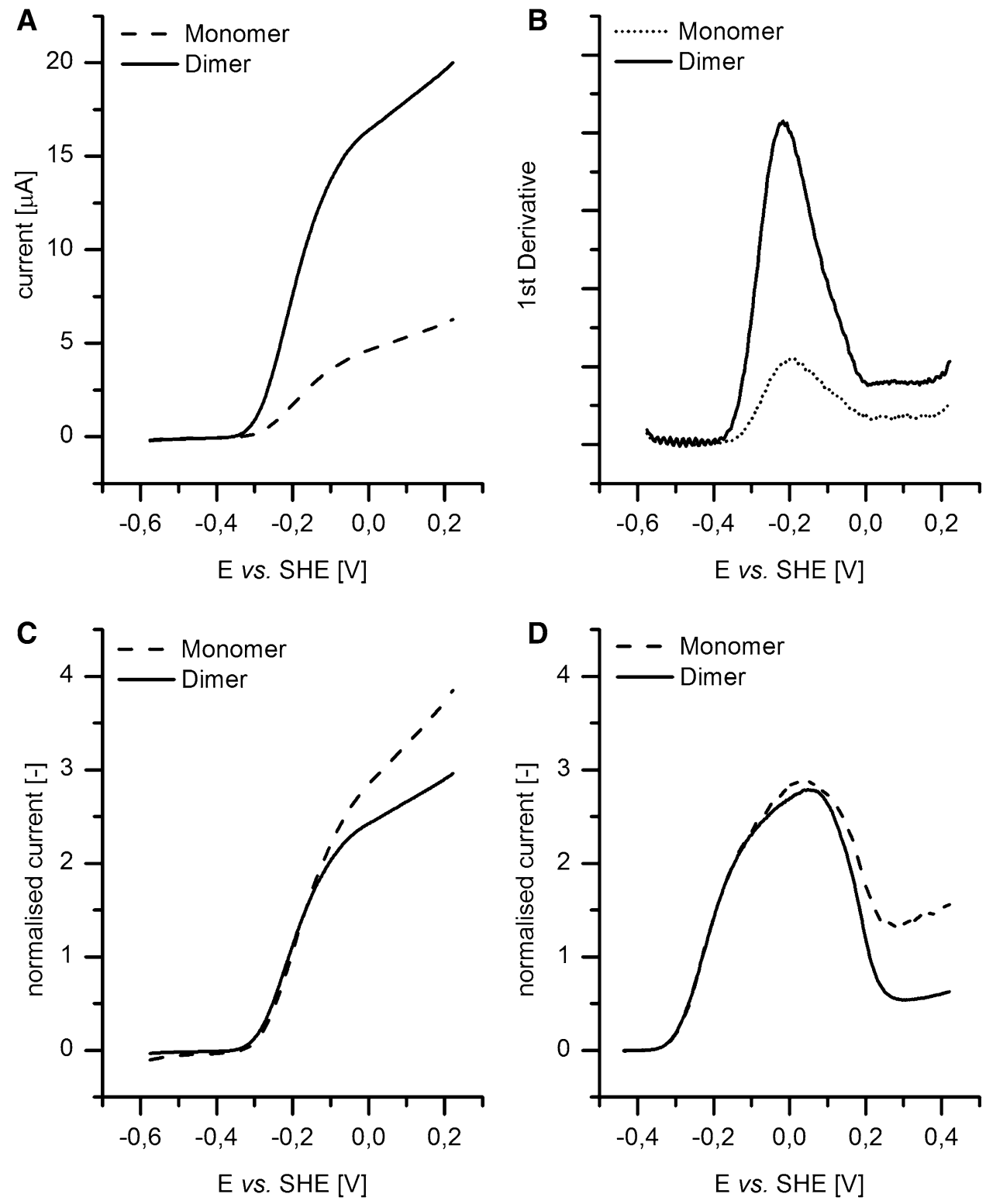

and $-212 \mathrm{mV}$ vs. SHE, respectively. By normalizing the voltammograms to the currents at these potentials, Fig. $6 \mathrm{c}$ was obtained: importantly, $\mathrm{H}_{2}$ oxidation by both oligomeric forms of Hyd-1 shows a nearly identical response at the low-potential edge where both show the same onset potential of approx. $-335 \mathrm{mV}$ vs. SHE at the conditions used. With the $\mathrm{H}_{2} / \mathrm{H}^{+}$equilibrium potential $E_{\text {eq }}$ at $-391 \mathrm{mV}$ vs. SHE, the onset overpotential requirement is approximately $56 \mathrm{mV}$ for both oligomeric forms.

At higher potential however, the two voltammograms differ significantly. Three factors principally affect the catalytic current of Hyd-1 at high potentials: (1) At sufficiently high currents, the current could be limited by $\mathrm{H}_{2}$ mass transport; this factor was eliminated by the use of 1 bar $\mathrm{H}_{2}$ and a rotation rate of $3000 \mathrm{rpm}$ (after establishing that a higher rotation rate did not result in an increase in current). (2) Dispersion of interfacial electron-transfer rates, due to the various orientations that can be adopted by enzyme molecules on an electrode surface, gives rise to a residual current instead of the flat plateau that is normally expected once electron transfer is no longer limiting [28]. (3) Slow oxidative conversion of the enzyme into the inactive $\mathrm{Ni}-\mathrm{B}$ state. A procedure was devised to assess the potential at which Ni-B is stable. The Hyd-1 film on the electrode was subjected to a high-potential poise $(+0.42 \mathrm{~V}$ vs SHE) for sufficient time to convert much of the sample to $\mathrm{Ni}-\mathrm{B}$, then the potential was scanned in the negative direction at a very low scan rate, e.g. $0.1 \mathrm{mV} \mathrm{s}^{-1}$. In such an experiment, shown in Fig. 6d, the data were normalized in the same way as those in panel $\mathrm{C}$, and the two traces overlay 
Fig. 7 Chronoamperometric experiments of $\mathrm{H}_{2}$ oxidation by dimer and monomer forms of Hyd-1 under increasing concentrations of $\mathrm{O}_{2}$. a General scheme showing how the $\mathrm{H}_{2}$ oxidation current of Hyd-1 dimer and monomer films was monitored at $10 \mathrm{mV}$ vs. SHE as the gas mixture is changed. The current is normalized with respect to the stable current under $100 \% \mathrm{H}_{2}$ After $400 \mathrm{~s} \mathrm{O}_{2}$ is added to the gas stream and removed again once the current has settled at a new stable level. The compositions of the $\mathrm{O}_{2} / \mathrm{H}_{2}$ atmospheres were: b $2.2 \% \mathrm{O}_{2}$, $97.8 \% \mathrm{H}_{2} ; \mathbf{c} 4.3 \% \mathrm{O}_{2}, 95.7 \%$ $\mathrm{H}_{2}$; d $10.0 \% \mathrm{O}_{2}, 90.0 \% \mathrm{H}_{2}$. Prior to each experiment the protein films on rotating PGE electrodes were activated at $-0.55 \mathrm{~V}$ vs. SHE and allowed to stabilize. Common conditions: $\mathrm{pH} 7.0$ electrode rotation rate $2500 \mathrm{rpm}$
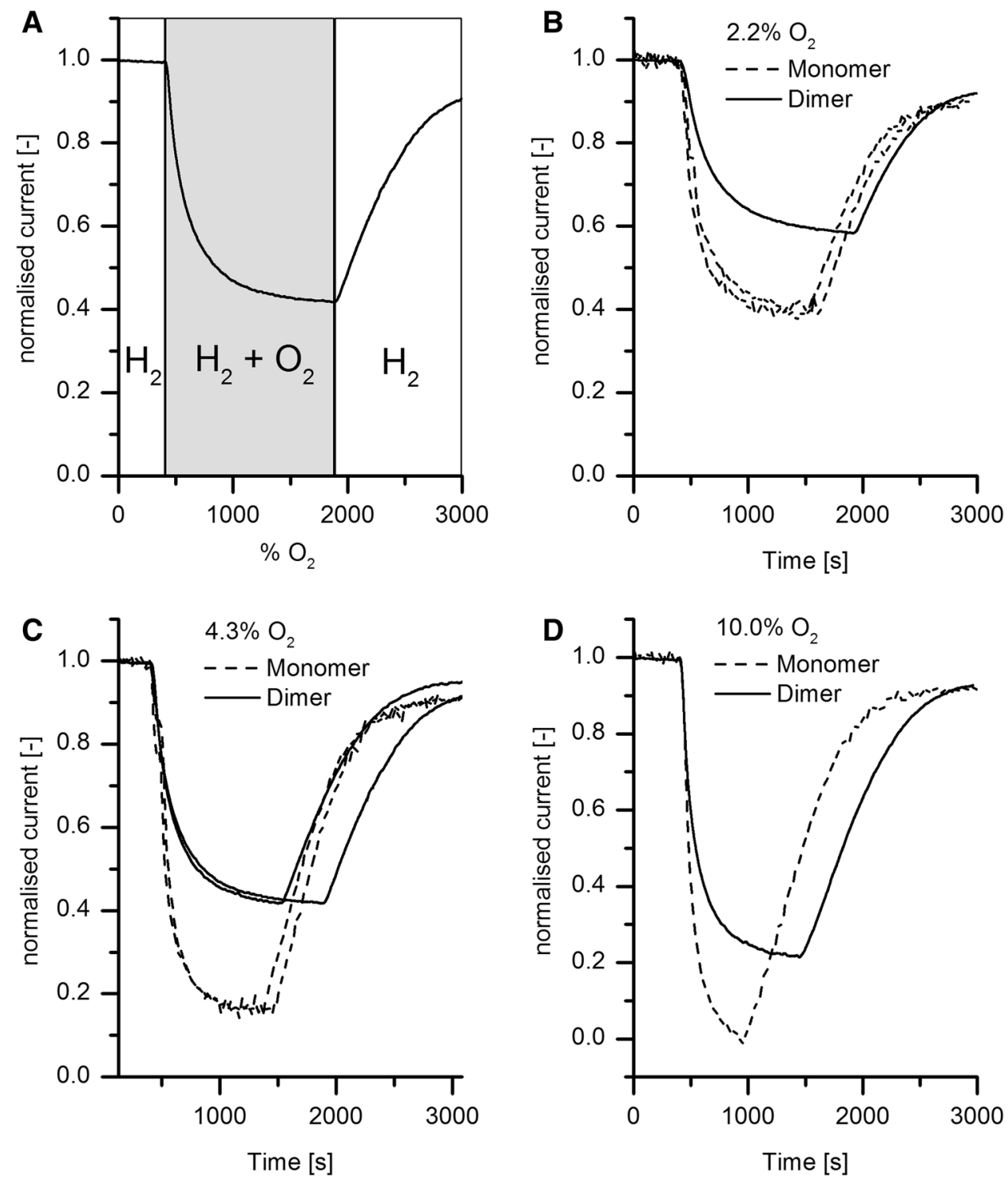

very well at low potential. Although the two voltammograms differ at high potential because the fraction of monomeric enzyme that has inactivated is smaller (the extent of anaerobic, electrochemical inactivation may depend on the proficiency of electronic coupling between enzyme and electrode) the re-activation potential referred to as $E_{\text {switch }}$ (an empirical reference point for the re-activation process) is altered very little.

The hallmark of oxygen tolerance is sustained activity in the presence of $\mathrm{O}_{2}$. Mass spectrometry results have shown that Hyd-1 achieves this through rapid reduction of $\mathrm{O}_{2}$ to water, which results only in Ni-B [11]. Chronoamperometric experiments on Hyd-1, in which the $\mathrm{H}_{2}$ oxidation current at a given potential was monitored during each addition and subsequent removal of $\mathrm{O}_{2}$ from the gas supply, showed that for each $\mathrm{O}_{2}$ concentration, the current settled at a new stable level, equivalent to $\mathrm{O}_{2}$ behaving as a reversible inhibitor [7]. A simple term for the fractional (steady-state) activity $f$ was introduced, $f$ being the steady-state $\mathrm{H}_{2}$ oxidation current for a given $\mathrm{O}_{2}$ level relative to that observed in the absence of $\mathrm{O}_{2}$. It was proposed that $f$ depends on the rates of inactivation $r_{\mathrm{I}}$ and reactivation $r_{\mathrm{A}}$ to/from the $\mathrm{Ni}-\mathrm{B}$ state according to Eq. 1:

$f=\frac{\text { Active enzyme }}{\text { Total enzyme }}=\frac{r_{\mathrm{A}}}{r_{\mathrm{A}}+r_{\mathrm{I}}}$.

Chronoamperometry experiments were carried out to determine how the oligomeric state of Hyd-1 affects the steady-state activity observed in the presence of different amounts of $\mathrm{O}_{2}$. The experiment was conducted at $10 \mathrm{mV}$ vs. SHE, a potential sufficiently high to have a good $\mathrm{H}_{2}$ oxidation current but, equally, negative enough to avoid anaerobic Ni-B formation. In Fig. 7a, the $\mathrm{H}_{2}$ oxidation rate under $100 \% \mathrm{H}_{2}$ was allowed to stabilize for $400 \mathrm{~s}$, 
providing the reference current by which the individual experiments could be normalized. Then $\mathrm{O}_{2}$ was introduced into the gas stream and the decreasing current was monitored for a period of time before the atmosphere was restored to $100 \% \mathrm{H}_{2}$. Panels B-D in Fig. 7 show the results of the $\mathrm{H}_{2} / \mathrm{O}_{2}$ experiment for monomer and dimer at different $\mathrm{O}_{2}$ concentrations. Although the $\mathrm{H}_{2}$ concentration varies from 100 to $90 \%$, this small range does not affect the current as these levels are far above the Michaelis constants which lie in the region of $1 \% \mathrm{H}_{2}$. The resulting catalytic current at each $\mathrm{O}_{2}$ addition is always lower for monomer. The currents for both dimer and monomer settle at new steady-state values for 2.2 and $4.3 \% \mathrm{O}_{2}$, but the monomer is unable to sustain $\mathrm{H}_{2}$ oxidation at $10 \mathrm{mV}$ vs. SHE in the presence of $10 \% \mathrm{O}_{2}$ and activity decreases to zero. In all cases however, restoring $100 \% \mathrm{H}_{2}$ results in rapid recovery, showing that inactivation is easily reversed, as expected if only $\mathrm{Ni}-\mathrm{B}$ is formed: hence monomer, like dimer is not converted into Unready states under these conditions.

\section{Discussion}

Use of freshly isolated Hyd-1 and digitonin proved not only to allow the clearest, most reliable separation of distinct dimer and monomer fractions, but also produced the least wastage in the form of aggregate. Although initially stable and soluble, aggregate fractions were observed to give substantial precipitate over time. Obtaining sufficient quantities of monomer was the chief challenge for a rigorous characterization of the monomer fraction, since only the trailing side of each monomer peak could be used to avoid isolating a heterogeneous sample. Applying very concentrated samples to a gel filtration column, in an effort to reduce the number of purifications needed to accumulate enough enzymes to study, tended to be futile, since loading concentrated samples lowers the peak separation.

The $(\alpha \beta: \alpha \beta)$ dissociation free energy of $31.8 \mathrm{kcal} / \mathrm{mol}$ (Table 1) for Hyd-1 is likely an overestimate since the underlying calculation does not account for the presence of detergent. From gel electrophoresis, both dimer and monomer as well as larger aggregate fractions consist of both small $(36.8 \mathrm{kDa})$ and large $(64.6 \mathrm{kDa})$ subunits. The ca. 210 and $104 \mathrm{kDa}$ oligomers are thus confidently assigned as dimer $(\alpha \beta)_{2}$ and monomer $(\alpha \beta)$.

The onset overpotential of approximately $+56 \mathrm{mV}$ (pH 6.5, $100 \% \mathrm{H}_{2}$ and $30{ }^{\circ} \mathrm{C}$ ) and the current response to increasing potential around the onset potential are similar for both monomer and dimer. Onset overpotential requirements for 'as-isolated' Hyd-1 were previously reported as approximately $+50 \mathrm{mV}$ under $10 \% \mathrm{H}_{2}\left(\mathrm{pH} 6.0,30{ }^{\circ} \mathrm{C}\right)$ by Lukey et al. [6], or in a more detailed study by Murphy and co-workers as $+54 \mathrm{mV}$ and $+82 \mathrm{mV}$ at $\mathrm{pH} 6.0$ and $\mathrm{pH} 7.0$, respectively ( $\left.100 \% \mathrm{H}_{2}, 37{ }^{\circ} \mathrm{C}\right)$ [4]. The values determined here for the pure oligomeric fractions agree well with these earlier measurements, noting that the onset potential increases with decreasing $\mathrm{pH}$ [4].

Differences in the voltammetry traces recorded for dimer and monomer are most prominent at high potential. The more pronounced residual current (slope) for monomer may reflect the ability of the (newly) solvent-exposed area in the monomer (i.e. the interface area in the dimer) to offer a greater range of interactions and orientations with the electrode surface. Importantly, the potential $E_{\text {switch }}$, a measure of the stability of $\mathrm{Ni}-\mathrm{B}$, is unchanged, and in conjunction with the similar onset overpotential, supports the idea that the Hyd-1 monomer is fully functional.

A particularly striking difference between monomer and dimer forms of Hyd-1 was displayed in the non-electrochemical, solution assays of $\mathrm{H}_{2}$ oxidation, where it was established that the initial lag phase for the monomer is more than twice as long as for the dimer (Fig. 4b). Questions arising are: (1) does the dimeric organization help in ensuring exclusive formation of rapidly reactivated $\mathrm{Ni}-\mathrm{B}$, and does the monomer therefore produce less-easily reactivated Unready states (Ni-A) ?. We noted earlier that Hyd-1 activity in solution is maintained at a constant level in $10 \% \mathrm{O}_{2}$, an observation that argues against $\mathrm{Ni}-\mathrm{A}$ formation [11]. (2) Does the dimeric organization affect the rates of reactivation of inactive states? (3) Can a result similar to the difference in lag phase be reproduced in a more controlled environment, where uncertainty over enzyme concentration is not important? The chronoamperometry experiments, in which Hyd-1 attains a steady state with simultaneous substrate $\left(\mathrm{H}_{2}\right)$ and competing substrate/ inhibitor $\left(\mathrm{O}_{2}\right)$ turnover, were helpful in answering these questions.

The facts that both dimer and monomer attain a steadystate $\mathrm{H}_{2}$ oxidation activity in the presence of $\mathrm{O}_{2}$ (Fig. 7) and recover activity fully when $\mathrm{O}_{2}$ is removed show that the ability to exclusively form $\mathrm{Ni}-\mathrm{B}$ (and no $\mathrm{Ni}-\mathrm{A}$ ) and thus reduce $\mathrm{O}_{2}$ completely to water are unaffected by the oligomeric state of the enzyme. Formation of even a small fraction of $\mathrm{Ni}-\mathrm{A}$ would lead to a persistent and largely irreversible decrease in catalytic current. Even under $10 \% \mathrm{O}_{2}$ the almost zero activity of the monomer recovers virtually completely when the $\mathrm{O}_{2}$ is removed from the gas stream. The main difference in all cases is that the fractional activity is significantly diminished for the monomer compared to the dimer. Further analysis of these steady-state levels holds the key to developing a plausible mechanistic explanation of the effects of dimerization.

Using the steady-state description introduced above, rates are substituted by rate constants: and assuming $r_{\mathrm{I}}=k_{\mathrm{I}}\left[\mathrm{O}_{2}\right]$ at the low $\left[\mathrm{O}_{2}\right]$ values used (Evans et al. measured the initial rate of $\mathrm{O}_{2}$ reaction with active Hyd-1 and 


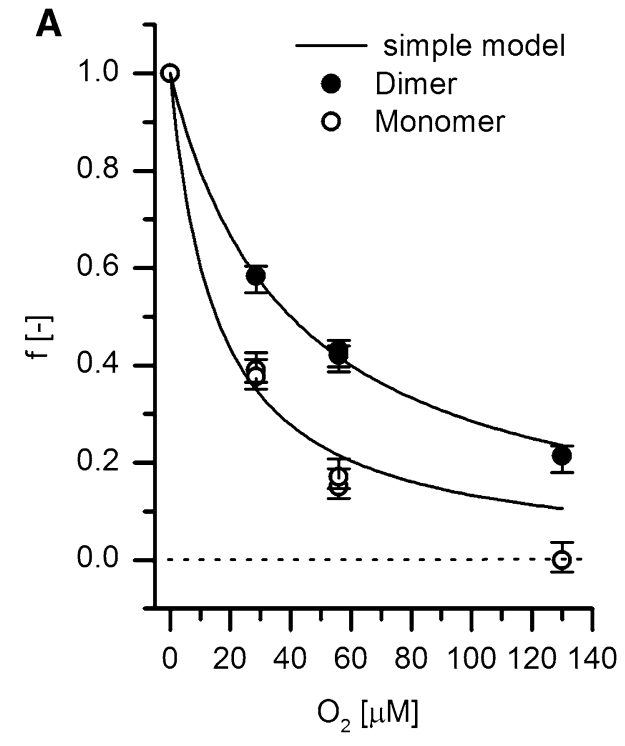

Fig. 8 Steady-state activities of dimer and monomer forms of Hyd1 , relative to initial activity, as a function of $\mathrm{O}_{2}$ concentration. The respective values were obtained from the chronoamperometry experiments shown in Fig. 7b-d. Error bars represent estimated uncertainty based on film loss, residual slope and electrical noise contributions. The zero current line is drawn as a dotted black line for reference.

found it to increase linearly with $\mathrm{O}_{2}$ concentration [7]), $f$ at any given potential is given by:

$f=\frac{\text { Active enzyme }}{\text { Total enzyme }}=\frac{k_{\mathrm{A}}}{k_{\mathrm{A}}+k_{\mathrm{I}}\left[\mathrm{O}_{2}\right]}$

Figure 8a shows a fit to Eq. 2 for the fraction of active dimer at each $\mathrm{O}_{2}$ concentration. The fit used a ratio $C$ of apparent reactivation to inactivation rate constant of $C_{\mathrm{D}} / \mu \mathrm{M}=k_{\mathrm{A}} / k_{\mathrm{I}}=40($ at $+10 \mathrm{mV})$. For the monomer, no fit could be obtained with any combination of rate constants; the best approximation was $C_{\mathrm{M}} / \mu \mathrm{M}=k_{\mathrm{A}} / k_{\mathrm{I}}=15$ with $k_{\mathrm{A}}$ being $38 \%$ that of the dimer.

Although the individual rate constants cannot be obtained directly from these experiments, previous experiments with Hyd-1 provide a guideline. Wulff et al. determined a rate constant of $k_{\mathrm{I}}=0.002\left(\mu \mathrm{M} \mathrm{O}_{2}\right)^{-1} \mathrm{~s}^{-1}$ at $20^{\circ} \mathrm{C}$ [11] while Evans et al. found $k_{\mathrm{I}}=0.0038\left(\mu \mathrm{M} \mathrm{O}_{2}\right)^{-1} \mathrm{~s}^{-1}$ at $30{ }^{\circ} \mathrm{C}$ [7]. From an Arrhenius plot, the rate constant for inactivation at $25{ }^{\circ} \mathrm{C}$ is estimated as $k_{\mathrm{I}}=0.0028(\mu \mathrm{M}$ $\left.\mathrm{O}_{2}\right)^{-1} \mathrm{~s}^{-1}$. With $C_{\mathrm{D}} / \mu \mathrm{M}=k_{\mathrm{A}} / k_{\mathrm{I}}=40$ (see above) the rate constant for reactivation is deduced to be $k_{\mathrm{A}}=0.112 \mathrm{~s}^{-1}$ for the presented fit to the dimer data. An interesting point, however, is that $k_{\mathrm{A}}$ is strongly potential dependent (see below). Since the reactivation rate is very fast at low potentials, it is not directly measurable under experimental conditions chosen to allow significant $\mathrm{H}_{2}$ oxidation activity at high $\mathrm{O}_{2}$ concentrations. This problem was addressed previously by Evans et al. [7] by extrapolation from data

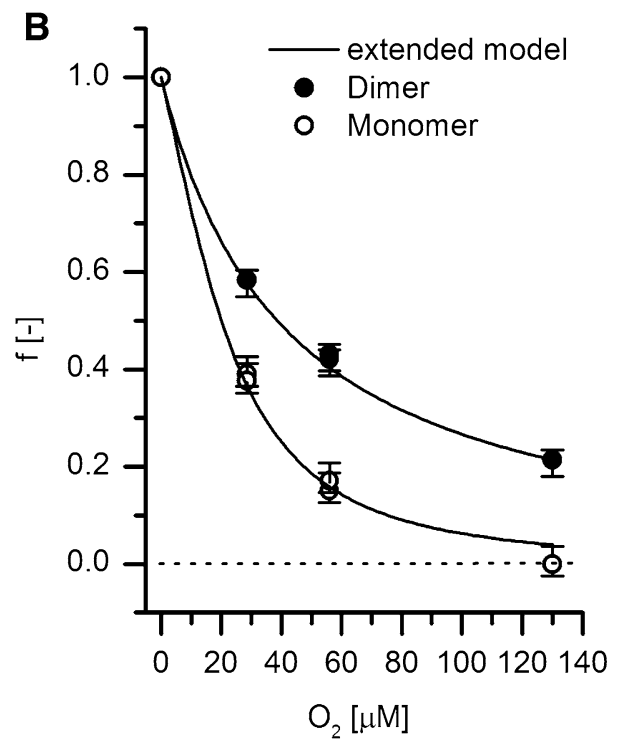

a Solid lines represent the fit to the simple model of $\mathrm{O}_{2}$ catalysis by Hyd-1 in the presence of $\mathrm{H}_{2}$ according to Eq. 2, as explained in the main text. b Solid lines represent the fit to the extended model (Eq. 4) based on oligomeric assembly, oxidative side reactions and electron transfer

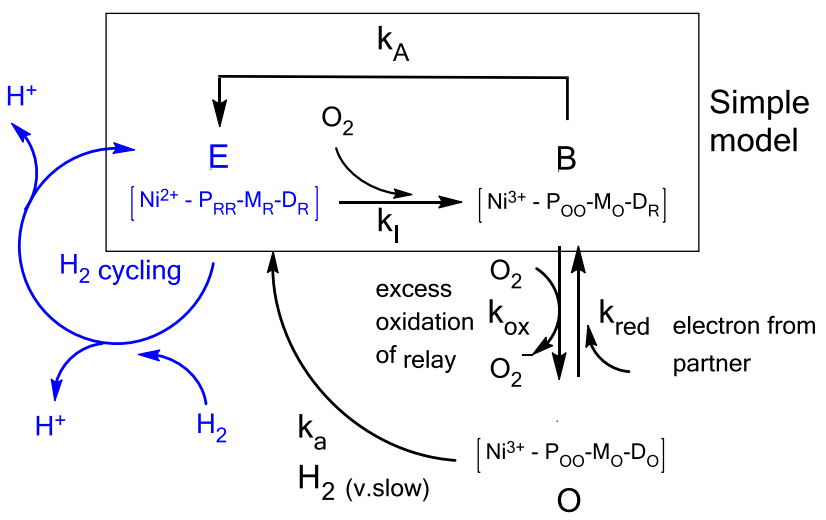

Scheme 1 Models for the reactions of Hyd-1 with $\mathrm{O}_{2}$ : the simple model, enclosed in the rectangle, assumes rapid reactivation of the enzyme by intramolecular electron transfer. The blue text represents enzyme that is active in $\mathrm{H}_{2}$ oxidation. Note that formation of $\mathrm{E}$ from B may also require the presence of $\mathrm{H}_{2}$ [29]

obtained at both higher potential and lower temperature to the desired conditions, with the help of electrochemical activation and Arrhenius plots. Using the same process, rate constants of $k_{\mathrm{A}}=0.136 \mathrm{~s}^{-1}$ and $k_{\mathrm{A}}=0.186 \mathrm{~s}^{-1}$ were calculated for $-10 \mathrm{mV}$ vs. SHE and $25{ }^{\circ} \mathrm{C}$ from two separate data sets in the paper by Evans et al.; the discrepancy between these two values illustrates the uncertainty and deviations introduced by double extrapolation. These calculations showed that the fit to the dimer data is achieved 
with rate constants that agree reasonably well with predicted values.

The simple model shown in Scheme 1 assumes that $\mathrm{O}_{2}$ attacks the active enzyme (E) when the active site is in the highest active oxidation state and all the $\mathrm{FeS}$ clusters are reduced. In the Ni-B state (B) that is rapidly formed, three electrons have been transferred from the $\mathrm{FeS}$ relay leaving one site (the distal cluster) still reduced. State B can be reactivated rapidly, starting with reduction of the active site $\mathrm{Ni}$ back to $\mathrm{Ni}^{2+}$ by intramolecular electron transfer, but the fact that $k_{\mathrm{A}}$ is a potential-dependent rate constant suggests that we should regard the FeS clusters of the relay collectively as acting like a low-level tunneling barrier-a 'wire' along which electron transfer is accelerated by a potential difference. The enzyme now re-enters the catalytic $\mathrm{H}_{2}$ cycle through binding of $\mathrm{H}_{2}$ and subsequent turnover [29]. Binding of $\mathrm{H}_{2}$ to the active site in the $\mathrm{Ni}^{2+}$ state to re-establish $\mathrm{E}$ is assumed to occur on a much faster time scale than the relatively slow reaction with $\mathrm{O}_{2}$, and is thus considered to be effectively instantaneous. After an indefinite number of $\mathrm{H}_{2}$ turnovers, another $\mathrm{O}_{2}$ may attack, and active enzyme $\mathrm{E}$ may enter another cycle of the slower $\mathrm{O}_{2}$ catalysis.

The simple model for the reaction of Hyd-1 with $\mathrm{O}_{2}$ was now reconsidered to see if any improvement could be made. An extension of the model needed to account for the observation that the active monomer fraction decreases more strongly than the active dimer fraction when the $\mathrm{O}_{2}$ concentration is increased; hence two further mechanistic features were introduced. First, it had been noted previously that a relatively small but significant superoxide/peroxide producing side reaction is observed for Hyd-1 in the presence of $\mathrm{O}_{2}$ [11]. Second, we considered the likelihood that the two partners in a dimer might be able to share electrons via the distal clusters. These considerations yielded the extended reaction scheme included in Scheme 1.

The first stage ocurs as before: $\mathrm{O}_{2}$ attacks an active enzyme molecule $\mathrm{E}$ to give $\mathrm{Ni}-\mathrm{B}$ (B in Scheme 1) in a fourelectron reaction that produces two molecules of water. If we assume that all the $\mathrm{FeS}$ clusters are reduced before $\mathrm{O}_{2}$ attacks, two electrons are delivered from the proximal $\mathrm{FeS}$ cluster $\mathrm{P}$, one stems from the medial cluster $\mathrm{M}$ and the final electron results from oxidation of the active site $\mathrm{Ni}$, such that the distal cluster D can remain reduced. Protons are omitted from this scheme which also aids simplicity. Under steady-state conditions $\mathrm{B}$ is best described as $\left(\mathrm{Ni}^{3+}\right.$ $\mathrm{P}_{\mathrm{OO}} \mathrm{M}_{\mathrm{O}} \mathrm{D}_{\mathrm{R}}$ ). Formation of a Michaelis complex E: $\mathrm{O}_{2}$ in the initial reaction of active enzyme with $\mathrm{O}_{2}$ was also considered but discarded, as a fit to the data simply required a very large $K_{\mathrm{m}}$ value to impose the same linearity as in the simpler model.

The extended model includes the possibility that inactive enzyme B may react in an alternative manner and become more oxidized, exhausting the $\mathrm{FeS}$ relay system of electrons. The electron residing in the FeS relay system that is normally available to transfer to the active site could transfer instead to another $\mathrm{O}_{2}$ molecule. Such a site is likely to be the distal cluster that lies closest to the protein surface and able to undergo an outer-sphere reduction of $\mathrm{O}_{2}$ to superoxide $\mathrm{O}_{2}^{-}$, resulting in a fully oxidized enzyme $\mathrm{O}$ that requires external electrons for re-activation. The source of this electron depends on the particular experiment (electrochemical vs solution), whether monomer or dimer is present, and on the rate constant $k_{\text {red }}$ for electron transfer to the distal cluster, specifically, either between subunits $\left(k_{\mathrm{DD}}\right)$ or interfacial $\left(k_{\mathrm{ED}}\right)$. It is very likely that the electron must tunnel over a longer distance from the electrode to the distal cluster than between the distal clusters, so that $k_{\mathrm{DD}} \gg k_{\mathrm{ED}}$. Thus, even on an electrode the dimer should have an advantage in $\mathrm{O}_{2}$ tolerance, since at any point in time it is likely to have at least one reduced distal cluster. Superoxide formation at the distal cluster could result in damage, although in the electrochemical experiment, $\mathrm{O}_{2}^{-}$would be removed rapidly by electrode rotation.

Another possible pathway for reactivation is the very slow reaction $\left(k_{\mathrm{a}}\right)$ of fully oxidized enzyme $\mathrm{O}$ with $\mathrm{H}_{2}$ to activate the enzyme, a process that accounts for the lag period in solution assays when no external electron donor is present. There is one precedent for this possibility, in which slow, direct reaction of Ready (Ni-B) with $\mathrm{H}_{2}$ is reported [30]. In the electrochemical experiment, when compared to reduction of the distal cluster by long-range electron transfers, $k_{\mathrm{a}}$ should be largely irrelevant for the dimer; hence, the overall rate of (dimer) reactivation $v_{\mathrm{A}}$ from $\mathrm{B}$ to $\mathrm{E}$ can be simplified by analogy to a reversible inhibition (Eq. 3) depending on $\left[\mathrm{O}_{2}\right]$ with an apparent inhibition constant $K_{\mathrm{C}}$ proportional to $k_{\text {red }} / k_{\mathrm{ox}}$ :

$v_{\mathrm{A}}=\frac{k_{\mathrm{A}}}{1+\frac{\left[\mathrm{O}_{2}\right]}{K_{\mathrm{C}}}}$.

Incorporation of $v_{\mathrm{A}}$ in place of $k_{\mathrm{A}}$ in Eq. 2 yields the fraction of active enzyme for the new extended model:

$f=\frac{\text { Active enzyme }}{\text { Total enzyme }}=\frac{k_{\mathrm{A}}\left(1+\frac{\left[\mathrm{O}_{2}\right]}{K_{\mathrm{C}}}\right)^{-1}}{k_{\mathrm{A}}\left(1+\frac{\left[\mathrm{O}_{2}\right]}{K_{\mathrm{C}}}\right)^{-1}+k_{\mathrm{I}}\left[\mathrm{O}_{2}\right]}$.

Incorporating this extension into the model improves the fit to the data at high $\mathrm{O}_{2}$ concentration even for the dimer (see Fig. 8b). The large value for $K_{\mathrm{C}}$ used for the dimer $\left(K_{\mathrm{C}}=1000\right)$ implies that distal cluster reduction via the distal-distal pathway is very fast compared to $k_{\mathrm{ox}}$, so that the oxidizing side reaction has a small effect which only becomes discernible at high $\mathrm{O}_{2}$ concentrations (where coinciding oxidation of both distal clusters in a dimer also becomes more probable). In the monomer, oxidation of the 
distal cluster in state $\mathrm{B}$ leaves only the slower $k_{\mathrm{ED}}$ contribution to $k_{\text {red }}$ and a much lower value for the constant $K_{\mathrm{C}}$ is expected. The slowest pathway for reactivation $k_{\mathrm{a}}$ might also play a small role under these circumstances. In agreement with these considerations, a good fit to the monomer data is obtained using the new extended model with $K_{\mathrm{C}}=20$ as shown in Fig. $8 \mathrm{~b}$.

Two further points are worth noting. The potentialdependence of the observed $k_{\mathrm{A}}$ values [7] is also consistent with the effect of electrode potential on distal cluster oxidation state and reverse supply of electrons $k_{\mathrm{ED}}$ for reactivation, as discussed above. The isotope ratio mass spectrometry experiment also supports the idea that the differences in $\mathrm{O}_{2}$ tolerance between dimer and monomer do not originate from separate pathways for primary $\mathrm{O}_{2}$ attack $\left(k_{\mathrm{I}}\right)$.

The excellent fit of the new extended model to the data for both dimer and monomer (Fig. 8b) is a strong argument for its validity. On a statistical basis, attacks by $\mathrm{O}_{2}$ molecules during normal $\mathrm{H}_{2}$ turnover are likely only to affect one half of the enzyme at a given instant unless the $\mathrm{O}_{2}$ concentration is very high. Rapid sharing of electrons between distal clusters for delivery to the active site, as described by the extended model, also explains why the lag phase in solution assays is much longer for monomer. According to Scheme 1, the lag phase is due to the very slow direct reaction with $\mathrm{H}_{2}\left(k_{\mathrm{a}}\right)$. For the dimer, only half of all active sites need to be reactivated via this slow pathway, explaining the observed ca. two fold difference in lag phase between dimer and monomer (Fig. 4). Once enzymes have become activated, electrons are available through the build up of reduced viologen and the process accelerates.

In conclusion, we have demonstrated that it is possible to separate distinct oligomeric states of E. coli Hyd-1. Specifically, an $(\alpha \beta)_{2}$ dimer of heterodimers and an $(\alpha \beta)$ monomer of heterodimers were isolated. The dimer is very stable, easy to isolate and is the favored species at increasing detergent concentrations where larger aggregate fractions are broken down. Experiments carried out to investigate the functional advantages that a dimer structure confers led to increased $\mathrm{O}_{2}$ tolerance as being the most significant property. The mechanism is complicated but we have proposed that $\mathrm{O}_{2}$ tolerance depends in some way on the ability to transfer electrons between the distal clusters in each $(\alpha \beta)$ monomer half. Just as the explanation for the fuel cell experiment lay in an analogy with jump-starting a car with a flat battery, the normal function of $\mathrm{Hyd}-1$, which is to catalyze $\mathrm{H}_{2}$ oxidation in the face of regular attacks by $\mathrm{O}_{2}$, depends upon the constant presence of a partner to provide a rescue electron when needed. Electron transfer between each half of the dimer is more rapid than interfacial electron transfer at modest electrochemical driving force. In conclusion, teamwork pays off even in biological electron transfer!
Acknowledgments Research was supported by the Biological and Biotechnological Sciences Research Council (Grants BB/H003878-1 and BB/I022309-1 to FAA and BB/H001190/1 and BB/I02008X/1 to FS) and St John's College, Oxford through award of a Graduate Scholarship to PW. F.A.A. is a Royal Society-Wolfson Research Merit Award holder. We thank Christopher Day for collaboration with mass spectrometry experiments. This paper is dedicated to the memory of R.J.P. 'Bob' Williams, who was a pioneer in understanding the diverse roles of metallic elements in biology.

Open Access This article is distributed under the terms of the Creative Commons Attribution 4.0 International License (http://creativecommons.org/licenses/by/4.0/), which permits unrestricted use, distribution, and reproduction in any medium, provided you give appropriate credit to the original author(s) and the source, provide a link to the Creative Commons license, and indicate if changes were made.

\section{References}

1. Fontecilla-Camps JC, Volbeda A, Cavazza C, Nicolet Y (2007) Chem Rev 107:4273-4303

2. Lubitz W, Ogata H, Rudiger O, Reijerse E (2014) Hydrogenases. Chem Rev 114:4081-4148

3. Vincent KA, Parkin A, Armstrong FA (2007) Chem Rev 107:4366-4413

4. Murphy BJ, Sargent F, Armstrong FA (2014) Energy Environ Sci 7:1426-1433

5. Hexter SV, Grey F, Happe T, Climent V, Armstrong FA (2012) Proc Natl Acad Sci 109:11516-11521

6. Lukey MJ, Parkin A, Roessler MM, Murphy BJ, Harmer J, Palmer T, Sargent F, Armstrong FA (2010) J Biol Chem 285:3928-3938

7. Evans RM, Parkin A, Roessler MM, Murphy BJ, Adamson H, Lukey MJ, Sargent F, Volbeda A, Fontecilla-Camps JC, Armstrong FA (2013) J Am Chem Soc 135:2694-2707

8. Pandelia M-E, Infossi P, Giudici-Orticoni MT, Lubitz W (2010) Biochemistry 49:8873-8881

9. Goris T, Wait AF, Saggu M, Fritsch J, Heidary N, Stein M, Zebger I, Lendzian F, Armstrong FA, Friedrich B, Lenz O (2011) Nat Chem Biol 7:310-318

10. Cracknell JA, Wait AF, Lenz O, Friedrich B, Armstrong FA (2009) Proc Natl Acad Sci 106:20681-20686

11. Wulff P, Day CC, Sargent F, Armstrong FA (2014) Proc Natl Acad Sci 111:6606-6611

12. Volbeda A, Martin L, Barbier E, Gutierrez-Sanz O, De Lacey AL, Liebgott PP, Dementin S, Rousset M, Fontecilla-Camps JC (2015) J Biol Inorg Chem 20:11-22

13. Volbeda A, Montet Y, Vernède X, Hatchikian EC, FontecillaCamps JC (2002) Int J Hydrogen Energy 27:1449-1461

14. Fritsch J, Scheerer P, Frielingsdorf S, Kroschinsky S, Friedrich B, Lenz O, Spahn CMT (2011) Nature 479:249-252

15. Shomura Y, Yoon KS, Nishihara H, Higuchi Y (2011) Nature 479:253-256

16. Volbeda A, Amara P, Darnault C, Mouesca JM, Parkin A, Roessler MM, Armstrong FA, Fontecilla-Camps JC (2012) Proc Natl Acad Sci 109:5305-5310

17. Bowman L, Flanagan L, Fyfe PK, Parkin A, Hunter WN, Sargent F (2014) Biochem J 458:449-458

18. Roessler MM, Evans RM, Davies RA, Harmer J, Armstrong FA (2012) J Am Chem Soc 134:15581-15594

19. Sawers RG, Boxer DH (1986) Eur J Biochem 156:265-275

20. Menon NK, Robbins J, Wendt JC, Shanmugam KT, Przybyla AE (1991) J Bacteriol 173:4851-4861 
21. Volbeda A, Damault C, Parkin A, Sargent F, Armstrong FA, Fontecilla-Camps JC (2013) Structure 21:184-190

22. Page CC, Moser CC, Chen XX, Dutton PL (1999) Nature 402:47-52

23. Wait AF, Parkin A, Morley GM, dos Santos L, Armstrong FA (2010) J Phys Chem C 114:12003-12009

24. Krissinel E, Henrick K (2007) J Mol Biol 372:774-797

25. Frielingsdorf S, Schubert T, Pohlmann A, Lenz O, Friedrich B (2011) Biochemistry 50:10836-10843

26. Radu V, Frielingsdorf S, Evans SD, Lenz O, Jeuken LJC (2014) J Am Chem Soc 136:8512-8515
27. Perica T, Marsh JA, Sousa FL, Natan E, Colwell LJ, Ahnert SE, Teichmann SA (2012) Biochem Soc Trans 40:475-491

28. Léger C, Jones AK, Albracht SPJ, Armstrong FA (2002) J Phys Chem B 106:13058-13063

29. Lamle SE, Albracht SPJ, Armstrong FA (2005) J Am Chem Soc 127:6595-6604

30. Kurkin S, George SJ, Thorneley RNF, Albracht SPJ (2004) Biochemistry 43:6820-6831 